\title{
Contexto social de vizinhança: percepções políticas na cidade de São Paulo
}

\section{Introdução}

Em uma democracia, teoricamente, as pessoas tomam sua decisão de voto de modo livre e independente. Entretanto, estudos sobre o comportamento eleitoral mostram que pessoas com as mesmas características sociais, socializadas a partir de certas crenças e que avaliam de forma parecida a situação político econômica presente, acabam votando numa mesma direção mesmo que suas decisões tenham sido tomadas de maneira diferente. Mais ainda, raramente as pessoas tomam suas decisões políticas de forma isolada. Geralmente elas se informam por meio das mídias de massa e das redes de comunicação política no contexto social onde vivem e praticam sua vida social (bairro onde mora, local de trabalho, clube, etc.), recebendo informações que podem reforçar ou contradizer as suas opiniões políticas. Os primeiros estudos do modelo sociológico de comportamento eleitoral de Columbia (Lazarsfeld; Berelson; Gaudet, 1948, Berelson et al 1954), argumentavam, por exemplo, que a escolha do voto seria influenciada pelas características sociológicas individuais das pessoas (religião, classe social, etc.) reforçadas pela interação com o contexto social à sua volta (família, colegas de trabalho, conhecidos, etc): “(...) a person thinks, politically, as he is, socially” (Lazarsfeld; Berelson; Gaudet,1948, p.27).

O presente artigo apresenta o resultado de uma pesquisa de survey realizada na cidade de São Paulo no ano de 2016, onde

Programa de Pós-Graduação em Geografia Humana, Universidade de São Paulo - Avenida Professor Lineu Prestes, 338 - CEP 05508-000 - Cidade Universitária. São Paulo, SP, Brasil. E-mail: <alekseizolner@gmail.com> Revista Brasileira de Ciência Política, nº 29. Brasília, maio - agosto de 2019, pp 189-222. 
encontramos evidências da percepção das pessoas sobre as opiniões políticas no contexto social onde vivem e como esta percepção afeta seu padrão de contato e comunicação política com seus vizinhos, analisando se o contexto social de vizinhança influencia ou não o comportamento eleitoral das pessoas.

Para Robert Huckfeldt $(1979,1986)$ o termo "vizinhança” não se refere a uma comunidade coesa de amigos e conhecidos mas sim ao local geográfico que um grupo de residentes compartilha enquanto que o "contexto social de vizinhança" se refere à composição social das pessoas que vivem nessa vizinhança ${ }^{2}$.

O conceito de "contexto" dentro da geografia política anglo-saxônica contemporânea, principalmente a partir da abordagem histórico-geográfica trazida pelos estudos de John Agnew (1987, 1996, 2002), adquiriu um sentido mais amplo referindo-se aos processos macrossociais espaço-temporais relacionados a certo "lugar" (micro) e que invariavelmente impactam nas atividades políticas locais (Agnew, 1996; Johnston, 2019). Aqui porém, adotamos uma noção contextual mais "fraca” (O’Loughlin, 2018) comumente utilizada na ciência política em estudos sobre o efeito de vizinhança (Huckfeldt, 1986, Johsnton; Pattie, 2006) e sobre a influência das redes sociais de comunicação local (Huckfeldt; Sprague, 1987), onde o "contexto" é entendido como o ambiente externo mais próximo ao indivíduo onde suas relações sociais ocorrem.

Dessa forma, o contexto social de vizinhança a que nos referimos no nosso estudo pode ser entendido como um "lugar" (distrito, bairro), com uma determinada composição social (nível de heterogeneidade social), onde os residentes que compartilham da mesma localidade geográfica podem ser influenciados politicamente por intermédio do contato via conversação com os seus vizinhos, em redes sociais locais, ou simplesmente observando a situação econômica e social local.

2 A partir desses conceitos o autor estuda o modo como as relações sociais e os padrões de interação social são estruturados pelos contextos sociais de vizinhança e como essas relações contextualmente estruturadas influem no comportamento político (Huckfeldt, 1986, p.2). 


\section{Contexto social e as redes de comunicação política: problema de pesquisa}

Estudos eleitorais na geografia, principalmente anglo-saxões (Agnew, 1987, 1996, 2002; Johsnton; Pattie, 2006), defendem dentro do modelo sociológico uma perspectiva contextual do comportamento eleitoral onde o eleitor na sua decisão seria influenciado tanto pelos aspectos composicionais, sua posição na sociedade (classe trabalhadora, classe média, etc,) como por aspectos contextuais, sua localização no espaço, o lugar onde vive e é socializado. Ou seja, o eleitor além das suas predisposições sociais seria também influenciado pelos elementos do meio social (mileux) do lugar onde vive e pratica sua vida cotidiana.

Um dos primeiros estudos que trouxe um modelo explicativo para a influência do contexto no comportamento eleitoral é o apresentado pelo geógrafo inglês Kevin Cox (1969 apud Johnston; Pattie, 2016). No seu estudo seminal sobre geografia eleitoral, Cox entende que o eleitor decide seu voto por meio das informações políticas que estejam ao seu alcance, tanto no sentido de proximidade geográfica (distancia espacial) como social (família, amigos próximos, colegas de trabalho, etc.). No seu modelo, o contexto onde as decisões de voto são tomadas é visto como uma rede onde as informações políticas são recebidas, processadas e enviadas por "nós”. A natureza da conexão e co-localização entre os "nós” modificaria a forma como as informações são difundidas no espaço. Alguns "nós” seriam mais eficientes do que outros no envio de informações políticas, como os formadores de opinião e pessoas fortemente partidárias terão mais tendência de omitir informações discordantes das suas opiniões preexistentes do que aquelas menos partidárias.

Estudos análogos sobre redes de contato e comunicação política (Hukcfeldt, 1986; Huckfeldt; Sprague, 1987; Huckfeldt, Plutzer, Sprague, 1993) indicam que o contexto social circunscreve as oportunidades de interação das pessoas, influenciando portanto na escolha pessoal de associação do indivíduo em grupos e em redes de comunicação política, trazendo situações cotidianas e opiniões 
que muitas vezes podem contradizer as predisposições sociológicas das mesmas.

Segundo William L. Miller (1977 apud Macallister et al. 2001), a interação social via conversação entre os indivíduos nos seus locais de moradia afeta as atitudes políticas e o comportamento eleitoral, e o contato social seria a condição para o consenso sobre as opiniões políticas. O indivíduo seria influenciado por quem conversa com ele: se a maioria dos seus contatos sociais apoia determinado partido ou opinião política, maior a probabilidade dessa pessoa ter a mesma posição. Caso a opinião pessoal seja oposta à maioria, o indivíduo pode sofrer (1) um processo de conversão, ou (2) reforçar a sua própria opinião contrária, principalmente quando envolve contextos e pessoas com status sociais diferentes, ou ainda (3) não ser influenciado pelo contato com os seus vizinhos, principalmente quando o indivíduo busca se isolar socialmente das redes de comunicação daquele ambiente.

Estudos, tanto nos EUA como na Inglaterra, indicam que as pessoas geralmente se comportam de forma consensual no contato com seus vizinhos. No estudo de Huckfeldt (1986) na cidade de Buffalo (EUA), membros da classe trabalhadora que moram nos bairros em que são maioria têm maior probabilidade de apoiar o Partido Democrata, enquanto que a tendência de membros da classe média serem democratas aumenta quanto mais amigos de classe trabalhadora têm e quanto mais trabalhador é o seu bairro de residência. No Reino Unido, estudos realizados nos anos 2000 (Macallister et al. 2001, Johnston; Pattie, 2006) mostram que o eleitor de qualquer origem social tem uma maior tendência de votar no partido que a maioria da população da sua área de residência apoia: por exemplo, em áreas mais pobres tanto os membros da classe trabalhadora como os da classe média tendem a apoiar mais o Partido Trabalhista.

As mídias de massa e as mídias sociais ${ }^{3}$ ao longo dos últimos anos vem "encurtando" a distância e disponibilizando cada vez

3 "Mídia social" aqui entendida como o meio que dá suporte às redes sociais na internet. 
mais informações às pessoas no lugar onde elas vivem, reduzindo teoricamente a influência do contexto geográfico nas suas decisões e opiniões políticas. Porém, estudos sobre relações sociais interpessoais (Mok, Wellman e Carrasco 2010) demonstram que a importância da distância para a formação de redes de comunicação e vínculos entre as pessoas (Granovetter, 1973), principalmente via contato face a face, teria se mantido inalterada da década de 1970 até a de 2000. Por outro lado, estudos recentes na geografia (Kellerman, 2016), mostram que a comunicação online facilita o desenvolvimento de vínculos entre as pessoas principalmente quando estes já existem no mundo real.

Como dito, as pessoas se informam cada vez mais via mídias de massa e mais recentemente pelas mídias sociais que estariam inclusive substituindo os ambientes tradicionais de socialização (escola, igreja, clubes, etc.) (Soukup, 2006). No entanto, para a perspectiva contextual sobre o comportamento eleitoral, a interpretação dessas informações pelos indivíduos inevitavelmente ocorre de maneira diferente de acordo com as suas características sociais em conjunto com os elementos encontrados no lugar onde vivem: características histórico-geográficas, economia local, composição social, étnica e etc. (Agnew, 1987, 1996).

Enquanto que em certa medida o contexto social cria situações cotidianas que podem trazer contradições com relação à opinião política das pessoas, estas buscam pertencer a redes sociais de comunicação onde seus membros tenham opiniões parecidas às suas, evitando assim a exposição a opiniões discordantes (Huckfeldt; Sprague, 1987). Em uma perspectiva analítica, as pessoas reduzem os custos de obtenção da informação política buscando como fonte indivíduos bem informados politicamente com pontos de vista semelhantes aos seus (Downs, 1999).

No entanto, posteriormente, Huckfeldt, Johnson e Sprague, (2004) em um estudo de painel onde se buscou mapear as redes sociais de comunicação política das pessoas, perceberam que grande parte dessas redes são heterogêneas em relação às opiniões políticas dos seus membros. A maioria das pessoas dentro dessas 
redes estão expostas a opiniões políticas dissonantes e contrárias às suas, em menor ou maior grau de intensidade, principalmente por causa da existência de "vínculos fracos" (Granovetter, 1973), ou seja, indivíduos que não interagem com todos os membros de uma mesma rede. Cada vínculo fraco em uma rede tem uma maior probabilidade de fornecer informações novas e não redundantes aos membros desta.

Essas redes também seriam espacialmente dispersas para além de um contexto social de vizinhança específico (Baybeck; Huckfeldt, 2002). Uma pessoa pode viver em um bairro residencial ou trabalhar em um determinado lugar mas não necessariamente compartilhar as mesmas redes de contato social e comunicação política dos seus vizinhos e colegas de trabalho sendo portanto, em teoria, menos influenciada pelo contexto geográfico e pela opinião política majoritária à sua volta.

Contextos que propiciam o contato e a exposição a indivíduos que não compartilham das mesmas redes de contato social e comunicação, a não ser o próprio vínculo entre eles, como o local de trabalho (Mutz; Mondak, 2006), aumentariam a chance do indivíduo entrar em contato com opiniões dissonantes às suas. Novamente, o estudo de Huckfeldt, Johnson e Sprague, (2004) mostra que pessoas pertencentes a redes menores e mais homogêneas tendem a ser mais partidárias por receberem apenas informações que favorecem o seu candidato e desfavorecem os adversários, enquanto que pessoas pertencentes a redes grandes e heterogêneas tendem a ter opiniões mais ambivalentes sobre os candidatos por estarem mais expostas a opiniões diversas e discordantes das suas.

Esse fenômeno também é observado nos dias atuais nas mídias sociais como Facebook, principalmente em relação à diversidade de informações políticas que o indivíduo recebe e é exposto, dependendo do grau de heterogeneidade em relação às opiniões políticas dos membros da sua rede de amigos (Bakshy; Messing; Adamic, 2015). No entanto, assim como o indivíduo no seu contexto de vizinhança pode reagir de forma reativa ao contato com os seus vizinhos (Miller 1977 apud Macallister et al. 2001), ou seja, reforçar 
a sua própria opinião contrária à maioria, estudos recentes (Bail et al 2018) também sugerem que indivíduos (principalmente de direita ou conservadores) expostos a informações politicas contrárias às suas nas mídias sociais (twitter) tornam-se mais polarizados e ativos na defesa dos seus próprios pontos de vistas.

Em um dos poucos trabalhos realizados no Brasil estudando a influência do contexto social no comportamento eleitoral, Baker, Ames e Rennó (2006), inspirados em Huckfeldt, Johnson e Sprague (2004), realizaram um estudo de painel com três ondas de entrevistas no ano de 2002 analisando a volatilidade do apoio político em relação aos candidatos à presidência naquele ano. Um dos achados dessa pesquisa é que os respondentes que residem em bairros heterogêneos com relação às opiniões políticas tendem a ser mais voláteis nos seus apoios eleitorais ao longo do tempo do que aqueles de bairros onde há uma maior homogeneidade. Mais ainda, o estudo de Baker, Ames e Rennó (2006) mostra que a maioria dos entrevistados tem consciência se a sua opinião política é parecida ou não à majoritária do seu contexto de vizinhança.

A partir dos estudos aqui levantados, tanto nas ciências sociais como na geografia, que defendem que o contexto, o lugar onde as pessoas vivem e tem suas relações sociais importa no comportamento eleitoral, esse artigo busca encontrar evidências dessa influência na cidade de São Paulo. Para isto investiga se os eleitores percebem ou tem consciência das opiniões políticas majoritárias dos lugares onde vivem, no caso o seu contexto social de vizinhança, o quanto a composição social desses contextos (grau de heterogeneidade) afeta essa percepção e o quanto essa percepção por sua vez afeta a opinião política e o padrão de interação interpessoal e de comunicação das pessoas.

\section{Desenho de pesquisa, dados e hipóteses}

Estudos sobre polarização política no Brasil indicam que mesmo que o nosso sistema partidário seja relativamente novo e os partidos políticos em termos de identificação partidária apresentem índices muito abaixo do esperado para um sistema minimamente 
estruturado, em relação às eleições presidenciais de 2002, 2006 e 2010, os eleitores apresentavam algum grau de simpatia pelos dois principais partidos, PT e PSDB (Braga; Pimentel Jr., 2011), e conseguiam se posicionar sobre assuntos de interesse e políticas públicas de uma forma relativamente alinhada às posições desses dois partidos (Samuels; Zucco, 2014). Mais ainda, nos últimos anos evidenciou-se um aumento da polarização partidária do eleitorado entre PT e PSDB, intensificado a partir dos eventos de Junho de 2013 e as eleições presidenciais de 2014 (Reis, 2014, Couto, 2014). No entanto, os eventos posteriores (eleição presidencial de 2018) sustentam a hipótese dessa polarização ser mais uma reação dentro dos setores médios e conservadores da sociedade contra o PT, trazendo argumentos para considerar a polarização nas opiniões pós-redemocratização orbitando em torno do PT em uma dicotomia petismo e antipetismo (Samuels; Zucco, 2018).

Em relação à cidade de São Paulo, desde a derrota de Paulo Maluf (PPB) para Marta Suplicy (PT) no segundo turno da eleição municipal de 2000, que significou na prática o fim da direita "malufista" que durante os anos 1990 foi protagonista na política municipal, em certa medida as eleições na cidade em todos os níveis de disputa (municipal, estadual e federal), com algumas exceções ${ }^{4}$, estiveram polarizadas entre PT e PSDB até 2016.

Uma tradição da geografia eleitoral é mapear a distribuição espacial dos votos de eleições subsequentes buscando identificar padrões estáveis de apoio eleitoral ao longo do tempo. A identificação desses padrões pode ajudar na compreensão dos componentes explicativos mais duradouros do comportamento eleitoral bem como trazer subsídios para predizer os padrões de voto futuros (Archer; Shelley, 1986). A literatura sobre a geografia eleitoral da cidade de São Paulo (Pierucci 1987,1989; Novaes, 1996; Figueiredo et al., 2002; Jacob, 2010) mostra que o apoio ao PT esteve associado às regiões mais periféricas da cidade, especialmente aquelas mais próximas aos municípios do ABC (Santo André, São Bernardo do Campo e

4 Em 2008 foi eleito prefeito o candidato do DEM Gilberto Kassab, vice de José Serra do PSDB que deixou o cargo em 2006 para concorrer ao governo do estado. 
São Caetano), porém só a partir dos anos 2000, assim como a nível nacional (Holzhacker; Balbachevsky, 2007), é que o partido passou a receber um apoio concentrado entre as classes sociais mais pobres (Frizzo, 2013). Já o PSDB, mesmo antes da sua viabilidade eleitoral, caracterizou-se por apresentar o seu maior apoio nas regiões mais ricas e centrais da cidade mas também foi preenchendo os espaços deixados pelos candidatos populistas de direita.

Em concordância com esses estudos e com o objetivo de identificar de uma forma mais precisa as regiões de apoio a PT e PSDB, utilizamos o método estatístico de análise fatorial denominado "S" (Archer; Taylor, 1981) que busca agrupar em fatores as regiões com padrões de votação parecidos em eleições consecutivas.

No caso da nossa pesquisa, analisou-se os resultados eleitorais desses dois partidos em porcentagem nas eleições presidenciais em primeiro turno de 2006 a $2014^{5}$ na escala de distritos administrativos da cidade de São Paulo. Usando o método de redução de valores "componentes principais" e o método de rotação fatorial ortogonal "Varimax", a análise fatorial resultou na extração de dois fatores explicando 98,7\% da variabilidade dos dados (anexo 1), representando respectivamente as regiões de apoio duradouro de PSDB e PT: Fator I, distritos mais centrais da cidade e Fator II, distritos mais periféricos.

Ao se identificar as regiões de apoio para ambos os partidos buscou-se analisar as percepções dos eleitores sobre os mesmos nos contextos sociais de vizinhança onde vivem por meio das seguintes hipóteses:

H1 - Espera-se que os entrevistados que tenham opinião política parecida com a histórica da região onde vivem considerem a sua opinião similar à do seu bairro e vice-versa.

H2 - Entre aqueles que consideram a sua opinião parecida espera-se que conversem mais sobre política com os seus vizinhos enquanto que aqueles que têm uma opinião contrária conversem

5 Resolveu-se utilizar os resultados das eleições 2006 a 2014 porque durante esse período ocorreu uma certa estabilidade dos padrões de votação para os dois partidos nas eleições presidenciais. 
menos isolando-se socialmente da rede de comunicação política local para evitar o desacordo ${ }^{6}$.

H3 - Espera-se que quanto mais homogêneo socialmente seja o bairro, maior a percepção das pessoas sobre qual o partido mais forte da região e consequentemente se a sua própria opinião política é similar ou diferente do seu contexto social de vizinhança. $\mathrm{Ou}$ seja, assumindo que a clivagem de classe ainda é um componente importante para polarização política na cidade de São Paulo (ricos/ PSDB e pobres/PT), em bairros socialmente homogêneos as pessoas teriam uma maior certeza de qual é o partido mais forte e ao mesmo tempo, comparando sua opinião com a da maioria, teriam um maior discernimento sobre se ela é similar ou diferente.

As hipóteses de trabalho foram testadas a partir de dados extraído de uma pesquisa de survey ${ }^{7}$ realizada em agosto de 2016 totalizando 1008 entrevistas presenciais em 57 distritos (anexo 2) localizados na região de apoio ao PSDB (figura 1) identificada pela análise fatorial (fator 1). As entrevistas foram realizadas dentro de setores censitários selecionados por sorteio e dentro desses setores censitários os entrevistados foram selecionados a partir de um sistema de cotas proporcionais ao universo de indivíduos, através das seguintes variáveis: sexo, faixa de idade, escolaridade e PEA (População Economicamente Ativa) (anexo 3). Em outras palavras, a amostra da pesquisa buscou representar de uma forma fidedigna a proporção de pessoas com essas caraterísticas (sexo, idade, escolaridade e PEA) no universo real de indivíduos nesses setores censitários segundo dados do censo do IBGE de 2010.

Utilizamos cinco perguntas desse survey no nosso trabalho. Duas sobre a opinião dos eleitores em relação a PT e PSDB, numa escala que vai de 0 a 10, e três perguntas que buscam compreender a percepção do eleitor sobre a opinião política em seu contexto social de vizinhança com o objetivo de testar as hipóteses do trabalho: (1) se comparada com as outras pessoas do bairro sua opinião política

Como no modelo de Miller (1977 apud Macallister et al. 2001).

Levantamento realizado pela consultoria APPC em Agosto de 2016. Os dados foram construídos com o mesmo rigor metodológico que se exige das pesquisas acadêmicas. 
é muito diferente, diferente, similar ou muito similar; (2) pelo que o entrevistado sabe ou ouviu falar, qual seria o partido político mais forte no seu bairro; (3) para analisar a modulação do seu padrão de interação social $(\mathrm{H} 2)$ perguntamos se o entrevistado costuma conversar sobre política com seus vizinhos (anexo 4).

Figura 1 - 0s 57 distritos administrativos de São Paulo cobertos pela pesquisa de survey de agosto de 2016.

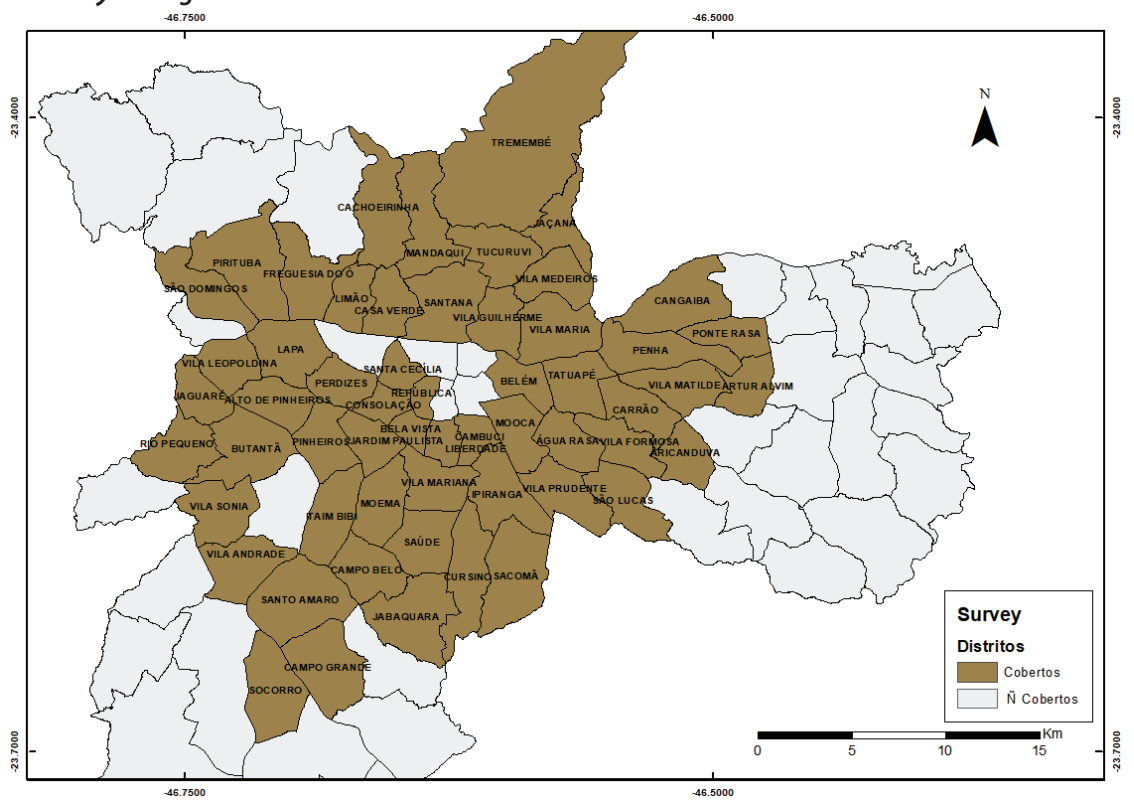

Fonte: IBGE, APPC, elaboração própria.

Em uma segunda etapa da pesquisa, com o objetivo de observar a alteração na percepção do entrevistado sobre a opinião política no seu bairro de residência de acordo com o grau de homogeneidade social do mesmo (H3), agrupamos os distritos cobertos pela pesquisa em quatro classes de renda a partir do número de residentes permanentes que ganham menos de dois salários mínimos (SM) (censo do IBGE de 2010). Consideramos como homogêneos os distritos agrupados na classe 1 (pobres) 80 a $71 \%$ de residentes 
com menos de dois SM e na classe 4 (ricos) até 30\% de residentes que ganham menos de dois SM e heterogêneos os distritos agrupados nas classes intermediárias (2 e 3 ).

Ao adotarmos esse critério de agregação estamos frente ao problema conhecido na literatura como MAUP (Modifiable Areal Unit Problem) (Openshaw, 1983; Tobler, 1989), que é a constatação de que dependendo de como as agregações das unidades geográficas ocorrem, os resultados estatísticos podem ser diferentes podendo alterar a grandeza e direção das relações encontradas entre as variáveis assim como a redução da significância estatística dos resultados (Linke; O’loughlin, 2015). No entanto, para Waldo Tobler (1989), quando as unidades espaciais são combinadas por uma razão justificada, o MAUP se torna irrelevante porque segundo ele o que importaria seria a racionalidade por trás dessa escolha de agregação.

Em uma análise contextual é comum a desagregação regional dos dados porém, se os dados de uma pesquisa não são planejados para esse tipo de análise como é o caso da nossa pesquisa, essa desagregação pode resultar em uma redução e disparidade do número de casos disponíveis para análise em cada unidade. Para minimizar esse problema da desagregação regional dos dados o agrupamento dos distritos foi feito de forma que o número de casos contidos em cada classe criada fosse relativamente uniforme (Figura 2, anexo 5). 
Figura 2 - 0s distritos administrativos de São Paulo cobertos pela pesquisa de survey divididos em 4 classes de acordo com o número de residentes que ganham menos de 2 salários mínimos (censo do IBGE 2010) de uma forma que o número de casos em cada classe seja relativamente parecido.

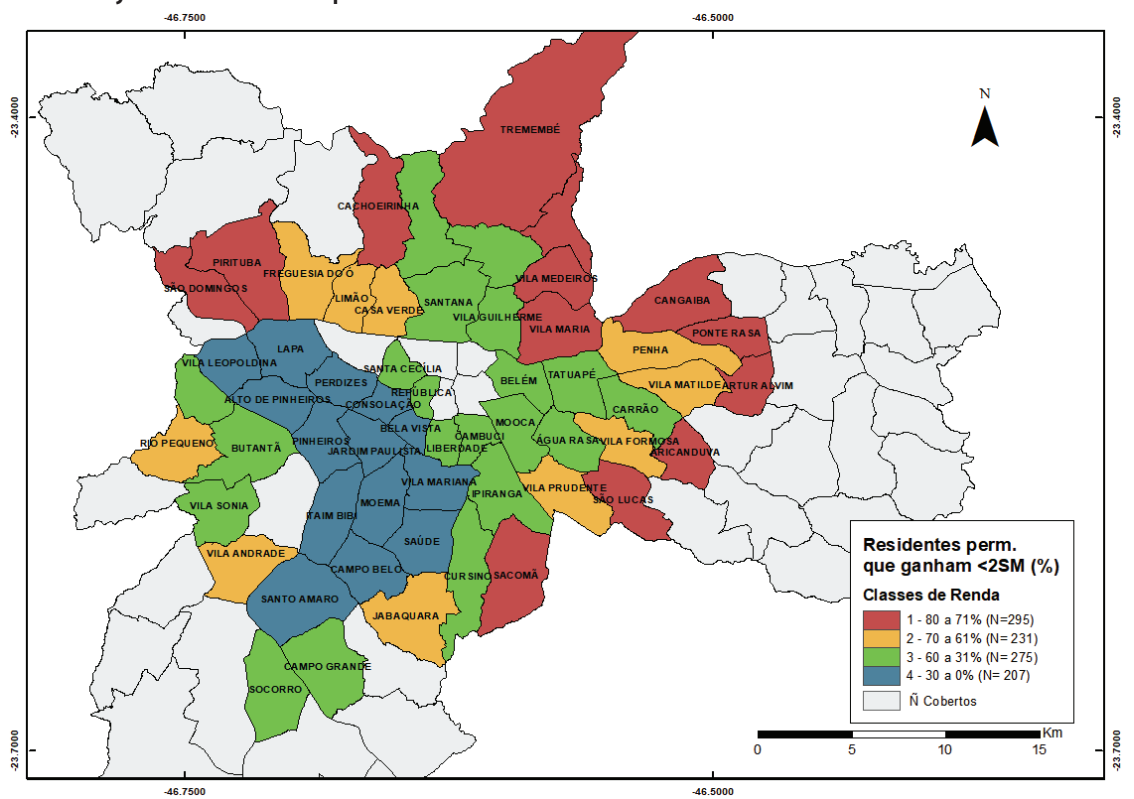

Fonte: IBGE, APPC, elaboração própria.

\section{Resultados da Pesquisa e discussão}

A opinião média sobre PT e PSDB (de 0 a 10) registrada pela pesquisa foi respectivamente de 2,54 e 3,82, com um desvio padrão para ambos os partidos de 3 pontos. Essa nota relativamente baixa para os dois partidos pode ser atribuída ao momento econômico político em que essa pesquisa foi realizada.

$\mathrm{O}$ ano de 2016 foi marcado pela crise econômica que atingiu o Brasil: PIB negativo de 3,6\% e taxa de desocupação acima dos $11 \%$ e pelas denúncias e investigações sobre corrupção no governo. No mês de agosto ocorreu também o impeachment da presidente Dilma Roussef do PT. Os reflexos desses acontecimentos na opinião política das pessoas podem ser sentidos na diminuição das taxas 
de identidade partidária: em Agosto de 2016 o Datafolha registrou a menor taxa de identidade partidária para o PT na série histórica, apenas 9\%. Ao mesmo tempo tivemos a maior taxa de eleitores que declaravam não ter nenhum partido de preferência, 70\% (gráfico 1).

Gráfico 1 - Identidade Partidária na cidade de São Paulo de 1988 a 2018

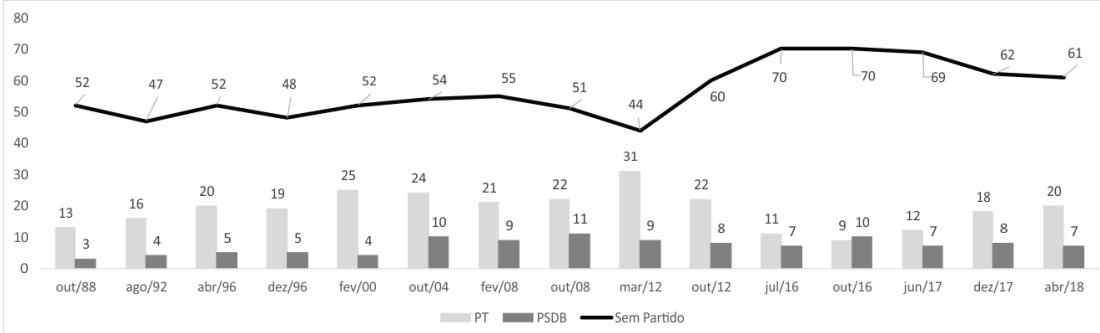

Fonte: Datafolha, elaboração própria

Apesar dessa aparente diminuição da identidade partidária no período, que teoricamente favoreceria uma diminuição da polarização do eleitorado (Fiorina e Abrams, 2008), foi possível a partir dos dados da nossa pesquisa de survey corroborar a nossa primeira hipótese de trabalho (H1) de que aqueles que manifestam ter uma opinião mais favorável ao partido com maior apoio histórico no lugar onde vivem percebem que a sua própria opinião é parecida à majoritária no seu contexto social de vizinhança. Considerando que os distritos mais centrais da cidade, onde essa pesquisa foi realizada, historicamente apoiam mais o PSDB, os dados da nossa pesquisa mostram uma diferença crescente ${ }^{8}$ na nota do partido entre os que dizem ter uma opinião diferente e os que afirmam ter opinião similar à do seu bairro. Enquanto que a média da avaliação sobre o partido entre os entrevistados que dizem ter uma opinião "Muito Diferente" e "Diferente" das outras pessoas do bairro é de 3,23 e 3,85 respectivamente, entre aqueles que consideram ter uma opinião "Similar" e "Muito Similar" ela passa para 4,38 e 4,51

8 Correlação Gama entre as variáveis gosta do PSDB (0 a 10) e similaridade nas opiniões (1 a 4) foi positiva com valor de 0,135, com erro padrão de 0,047 e significância estatística de 0,04 valor p. 
respectivamente. Esses dados apontam, portanto, que nesse caso ${ }^{9} \mathrm{o}$ eleitor mediano percebe se sua opinião política é semelhante ou não à do seu contexto social de vizinhança.

Aplicando um modelo de regressão ordinal multivariada, usando como variáveis composicionais de controle: idade, instrução, renda e PEA, os resultados mostram que o indivíduo com menor renda, empregado (PEA), que conversa sobre política com os seus vizinhos e melhor avalia o PSDB considera sua opinião mais similar à do seu bairro (tabela 1). Apesar da variável renda apresentar um resultado aparentemente contraditório considerando que indivíduos com menor renda, principalmente após o segundo governo Lula, estão associados a um apoio ao PT (Holzhacker; Balbachevsky, 2007), esse modelo corrobora $\mathrm{H} 1$ ao mostrar uma relação positiva entre gostar do PSDB e considerar a sua opinião política parecida à do seu contexto social de vizinhança.

Tabela 1 - Regressão multivariada ordinal: Similaridade das opiniões de acordo com algumas variáveis.

Comparado com as outras pessoas do seu bairro, você diria que a sua opinião política é: (1) Muito Diferente, (2) Diferente, (3) Similar ou (4) Muito Similar.

\begin{tabular}{lcccc}
\hline Variáveis & Estimativa & Erro padrão & Wald & Sig. \\
\hline Limite (Threshold) & & & & \\
Similaridade (1) & $-3,137^{* * *}$ & 0,541 & 33,631 & 0,000 \\
Similaridade (2) & $-1,315^{* *}$ & 0,525 & 6,286 & 0,012 \\
Similaridade (3) & $1,396^{* *}$ & 0,530 & 6,941 & 0,008 \\
\hline Faixa de Idade & & & & \\
16 a 24 & $-0,408$ & 0,313 & 1,700 & 0,192 \\
25 a 44 & $-0,227$ & 0,242 & 0,880 & 0,348 \\
45 a 59 & 0,334 & 0,257 & 1,682 & 0,195 \\
$>=60$ anos & - & - & - & - \\
Faixa de Instrução & & & & \\
Ensino Fundamental & $-0,257$ & 0,246 & 1,095 & 0,295 \\
& & & & \\
\hline 9 & & & &
\end{tabular}




\begin{tabular}{lcccc} 
Médio & 0,040 & 0,184 & 0,047 & 0,829 \\
Superior & - & - & - & - \\
Renda & $-0,435^{*}$ & 0,187 & 5,374 & 0,020 \\
PEA & $0,391^{*}$ & 0,186 & 4,436 & 0,035 \\
Conversa sobre política com os vizinhos & $-0,426^{* *}$ & 0,167 & 6,469 & 0,011 \\
Gosta do PT (0 a 10) & $-0,022$ & 0,025 & 0,767 & 0,381 \\
Gosta do PSDB (0 a 10) & $0,058^{*}$ & 0,026 & 5,024 & 0,025 \\
\hline Qui- Quadrado & $35,897 * * *$ & & & 0,000 \\
Pseudo R Ragelkerke & 0,070 & & & \\
N & 551 & & & \\
\hline
\end{tabular}

Fonte: APPC, elaboração própria.

Notas: Valor-p: $* * * 0,001, * *<0,01, *<0,05$.

Variáveis: Idade: (1) = 16 a 24, (2) = 25 a 44, (3) = 45 a 59, (4) >= 60 anos; Instrução: (1) = Ensino Fundamental, (2) = Médio,

(3) = Superior; Renda: (1) = Até 2 SM, (2) = Mais de 2SM; PEA: (0) = Não, (1) = Sim; Conversa sobre política com os vizinhos:

$(0)=$ Não, (1) = Sim; Gosta do PT (0 a 10); Gosta do PSDB (0 a 10).

Para testar a segunda hipótese da pesquisa $(\mathrm{H} 2)$ de que pessoas que consideram ter opiniões parecidas às dos seus contextos sociais de vizinhança costumam conversar mais sobre política com os seus vizinhos, analisamos isoladamente a relação entre as variáveis "conversar sobre política com os vizinhos" e "similaridade nas opiniões políticas". Os resultados dessa análise apresentam evidencias que corroboram $\mathrm{H} 2$ : há um aumento crescente de respondentes, em porcentagem, dos que dizem conversar sobre política quanto maior a similitude em relação à opinião política do seu bairro (ver tabela 2). Enquanto apenas $44 \%$ dos respondentes que dizem apresentar uma opinião diferente do seu bairro costumam conversar sobre política com seus vizinhos, $84 \%$ dos respondentes que dizem ter uma opinião similar alegam conversar sobre política com os vizinhos. Esses dados podem ser interpretados como uma evidência de que os indivíduos modulam os seus padrões de interação social (conversar sobre política) de acordo com a opinião política majoritária dos lugares onde vivem, com o objetivo de evitar o desacordo e serem expostos e influenciados por informações conflitantes. Em outras palavras, se a pessoas consideram sua opinião parecida à dos seus vizinhos, elas irão compartilhar mais 
suas posições políticas do que aquelas que têm uma percepção da sua opinião política ser diferente.

Tabela 2 - Tabela cruzada entre as variáveis "similaridade nas opiniões políticas" e "conversar sobre política com os vizinhos".

\begin{tabular}{ccccc}
\hline \multirow{2}{*}{$\begin{array}{c}\text { Conversa sobre com } \\
\text { os seus vizinhos }\end{array}$} & \multicolumn{5}{c}{ Comparado com as outras pessoas do seu bairro, você diria que a sua opinião política é: } \\
\cline { 2 - 5 } & Muito Diferente & Diferente & Similar & Muito Similar \\
\hline Sim & $30(44,8 \%)$ & $92(50,3 \%)$ & $150(52,8 \%)$ & $44(84,6 \%)$ \\
\hline Não & $37(55,2 \%)$ & $91(49,7 \%)$ & $134(47,2 \%)$ & $8(15,4 \%)$ \\
\hline Total & $67(100 \%)$ & $183(100 \%)$ & $284(100 \%)$ & $52(100 \%)$ \\
\hline Correlação Gama & \multicolumn{5}{c}{$0,233(0,065)^{* * *}$} \\
\hline N & \multicolumn{5}{c}{586} \\
\hline
\end{tabular}

Fonte: APPC, elaboração própria.

Notas: Erro padrão entre parênteses. Valor-p: $* * * 0,001, * *<0,01, *<0,05$.

Variáveis: Conversa sobre política com os vizinhos: $(0)=$ Não, $(1)=$ Sim; Comparado com as outras pessoas do seu bairro, você diria que a sua opinião política é: (1) Muito Diferente, (2) Diferente, (3) Similar ou (4) Muito Similar.

Como vimos, os distritos cobertos pela pesquisa são aqueles onde o PSDB historicamente recebe maior apoio eleitoral. Quando perguntamos qual seria o partido político mais forte do bairro na opinião do entrevistado, excluindo aqueles que não souberam e não responderam, $48 \%$ das pessoas disseram ser o PSDB o partido mais forte enquanto que 37\% responderam ser o PT (Figura 3). Essa porcentagem alta para o PT, principalmente nos distritos da zona leste, talvez possa ser atribuída à história operária destes e que permaneceu na memória dos seus moradores atuais. 
Figura 3 - Partido mais forte no bairro segundo os entrevistados.

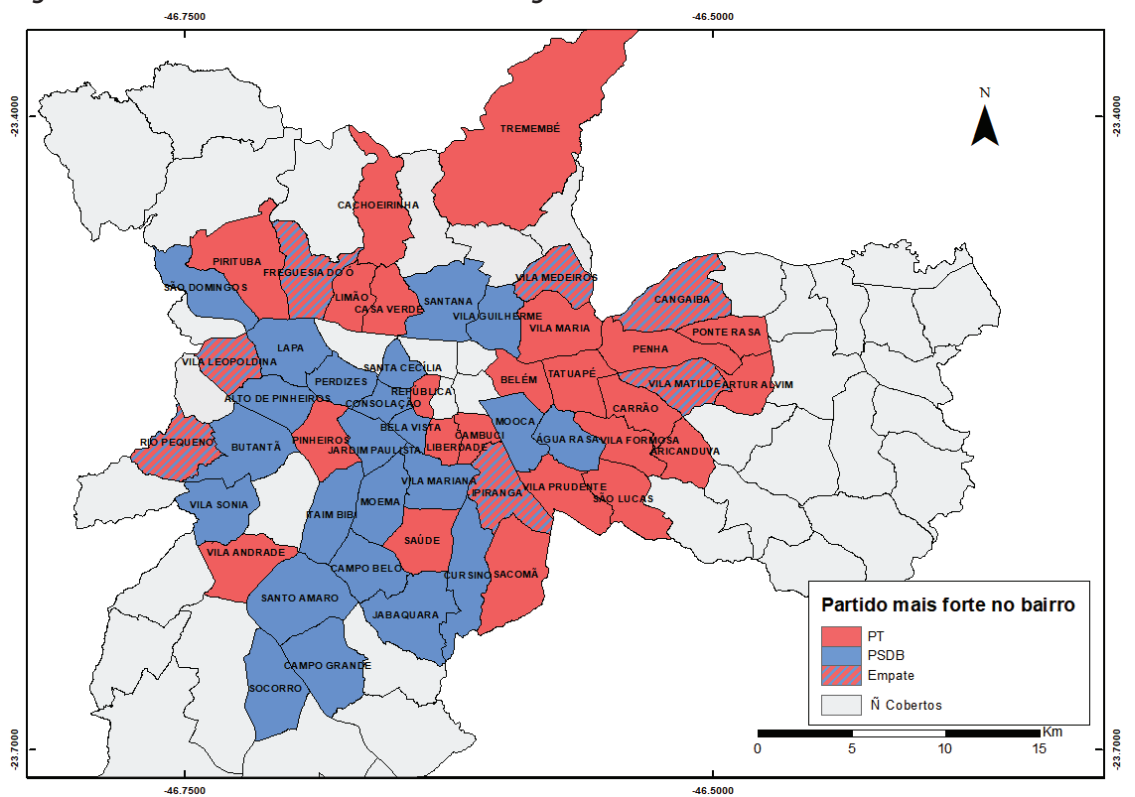

Fonte: IBGE, APPC, elaboração própria.

Retomando a nossa primeira hipótese (H1), mas agora separando os entrevistados entre aqueles que consideram o PSDB ou PT o partido mais forte respectivamente, no grupo de pessoas para as quais o PSDB é o partido mais forte no seu bairro aquelas que gostam mais desse partido tendem a considerar sua opinião similar à majoritária ${ }^{10}$ enquanto que aquelas que gostam mais do $\mathrm{PT}$ consideram sua opinião diferente ${ }^{11}$. Já no grupo de pessoas para as quais o PT é o partido mais forte do bairro, tanto aquelas que gostam do $\mathrm{PT}^{12}$ quanto as que apoiam o $\mathrm{PSDB}^{13}$ consideram sua opinião similar à maioria (tabela 3 ).

10 Média da opinião sobre o PSDB entre aqueles consideram o PSDB o partido mais forte: Muito diferente: 3,21; Diferente: 4,15; Similar: 5,52 e Muito Similar: 7,60

11 Média da opinião sobre o PT entre aqueles consideram o PSDB o partido mais forte: Muito diferente: 4,68; Diferente: 2,65; Similar: 1,23 e Muito Similar: 0,60

12 Média da opinião sobre o PSDB entre aqueles consideram o PT o partido mais forte: Muito diferente: 3; Diferente: 3,46; Similar: 3,79 e Muito Similar: 4,13

13 Média da opinião sobre o PT entre aqueles consideram o PT o partido mais forte: Muito diferente: 2,63; Diferente: 4,46; Similar: 4,13 e Muito Similar: 7,20 
Tabela 3 - Correlação gama entre a opinião sobre PSDB e PT a variável "similaridade nas opiniões políticas" entre aqueles que consideram PSDB ou PT o partido mais forte no bairro.

Comparado com as outras pessoas do seu bairro, você diria que a sua opinião política é: (1) Muito Diferente, (2) Diferente, (3) Similar ou (4) Muito Similar.

\begin{tabular}{ccccc}
\hline $\begin{array}{c}\text { Considera como partido } \\
\text { mais forte no bairro }\end{array}$ & \multicolumn{2}{c}{ PSDB } & PT \\
\hline Gosta do partido (0a 10) & PSDB & PT & PSDB & PT \\
\cline { 2 - 5 } & $0,314(0,088)^{* * *}$ & $-0,436(0,088)^{* * *}$ & $0,136(0,099)$ & $0,260(0,102)^{* *}$ \\
\hline$N$ & 144 & 144 & 109 & 110 \\
\hline
\end{tabular}

Fonte: APPC, elaboração própria

Notas: Erro padrão entre parênteses. Valor-p: ${ }^{* * *}<0,001,{ }^{* *}<0,01,{ }^{*}<0,05$.

Finalmente, testamos a terceira hipótese do trabalho (H3) de que quanto mais socialmente homogêneo é o bairro, maior a certeza do entrevistado sobre qual é o partido mais forte na região e ao mesmo tempo se sua opinião política é similar ou diferente à dos seus vizinhos. Desagregando regionalmente os dados e agrupando em 4 classes os distritos onde a pesquisa de survey foi realizada, de acordo com o número de residentes permanentes que ganham menos de 2 salários mínimos, encontramos que quanto mais rico o bairro em relação à renda dos seus habitantes (classe 4: de 30 a 0\% $<=2$ salários mínimos) maior a porcentagem de pessoas que identificam o PSDB como o partido mais forte no bairro (gráfico 2) ${ }^{14}$.

14 Podemos especular que se essa pesquisa atingisse também os distritos mais pobres da cidade, o mesmo aconteceria com as pessoas dos bairros mais pobres identificando o PT como o partido mais forte. 
Gráfico 2 - Porcentagem de entrevistados que consideram PT ou PSDB como o partido mais forte no seu bairro por distritos agregados de acordo com a classe de renda.

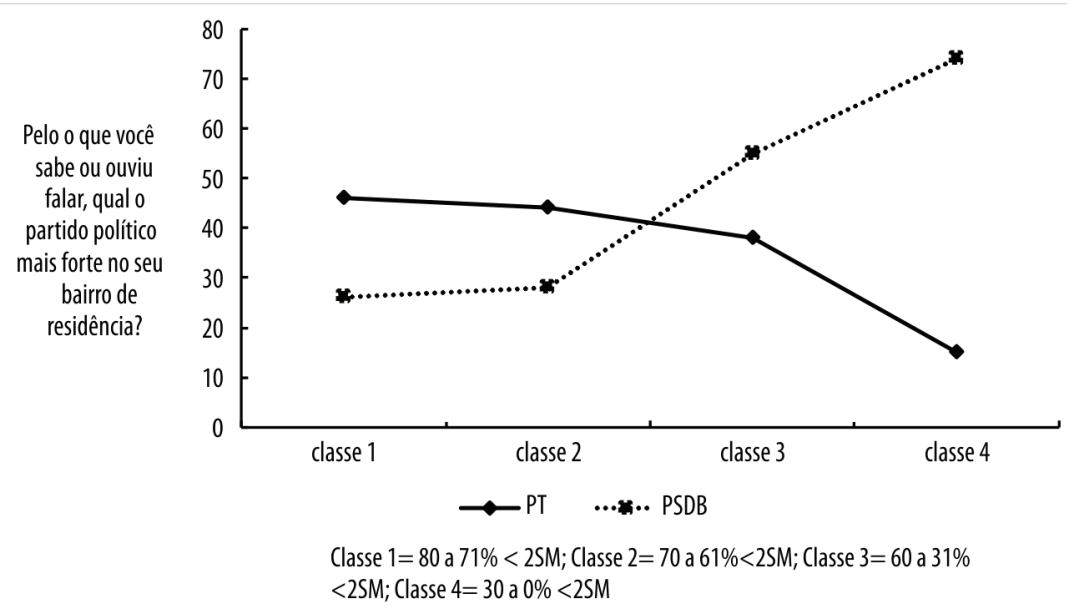

Fonte: APPC, elaboração própria.

Quando analisamos nesses distritos agrupados a relação entre a pergunta sobre similaridade nas opiniões políticas e a avaliação dos entrevistados sobre o PSDB, encontramos que quanto mais "rico" é o bairro, maior é a diferença na avaliação dos entrevistados sobre o partido: aqueles que consideram sua opinião similar gostam mais do partido e os que consideram sua opinião diferente gostam menos (gráfico 3). Nos bairros de classe 4, aqueles que consideram a sua opinião muito diferente dos seus vizinhos dão em média uma nota muito mais baixa ao $\operatorname{PSDB}(2,13)$ dos que aqueles que consideram ter uma opinião similar $(5,19)$ ou muito similar $(4,78)$. Esse resultado aparentemente indica que nos bairros mais ricos, ao mesmo tempo que os entrevistados identificam mais facilmente o PSDB como sendo o partido mais forte, existe uma maior polarização das opiniões sobre o partido e uma maior percepção do eleitor na relação da sua própria opinião com a dos vizinhos, ou seja, aquele que gosta do partido tem uma maior certeza que a sua opinião é similar, enquanto que o eleitor que não gosta do PSDB tem uma maior convicção de que sua opinião é diferente. 
Já em relação à opinião sobre o PT, observamos uma discrepância na avaliação do partido entre os que consideram sua opinião similar ou diferente, tanto nos bairros mais ricos (classe 4), quanto nos bairros mais pobres (classe 1), principalmente quando consideramos apenas as respostas superlativas ("muito similar" e "muito diferente"). Esse resultado indica que enquanto para o PSDB apenas nos bairros ricos as pessoas têm certeza que o partido é o mais apoiado conseguindo assim identificar melhor a similaridade ou diferença da sua opinião, para o PT tanto as pessoas dos bairros mais pobres têm consciência de que a maioria apoia o partido, quanto as pessoas dos bairros mais ricos sabem que o partido é rejeitado na sua vizinhança (gráfico 4).

Esses últimos resultados de certa forma corroboram $\mathrm{H} 3$ pelo menos em relação ao PT. Ou seja, nos bairros socialmente mais homogêneos (classe 1 e classe 4) o eleitor tem uma percepção mais nítida de que o partido (PT) tem maior ou menor apoio na região e se sua própria opinião é similar ou diferente. Para o PSDB, H3 ocorre só nas regiões ricas (classe 4) sugerindo que a percepção em relação ao partido não talvez tenha relação com homogeneidade. 
Gráfico 3 - Média da opinião das pessoas sobre se gostam do PSDB (0 a 10), nos distritos agrupados por classe de renda, de acordo com a percepção do eleitor sobre se a sua opinião é similar ou diferente com relação à maioria.

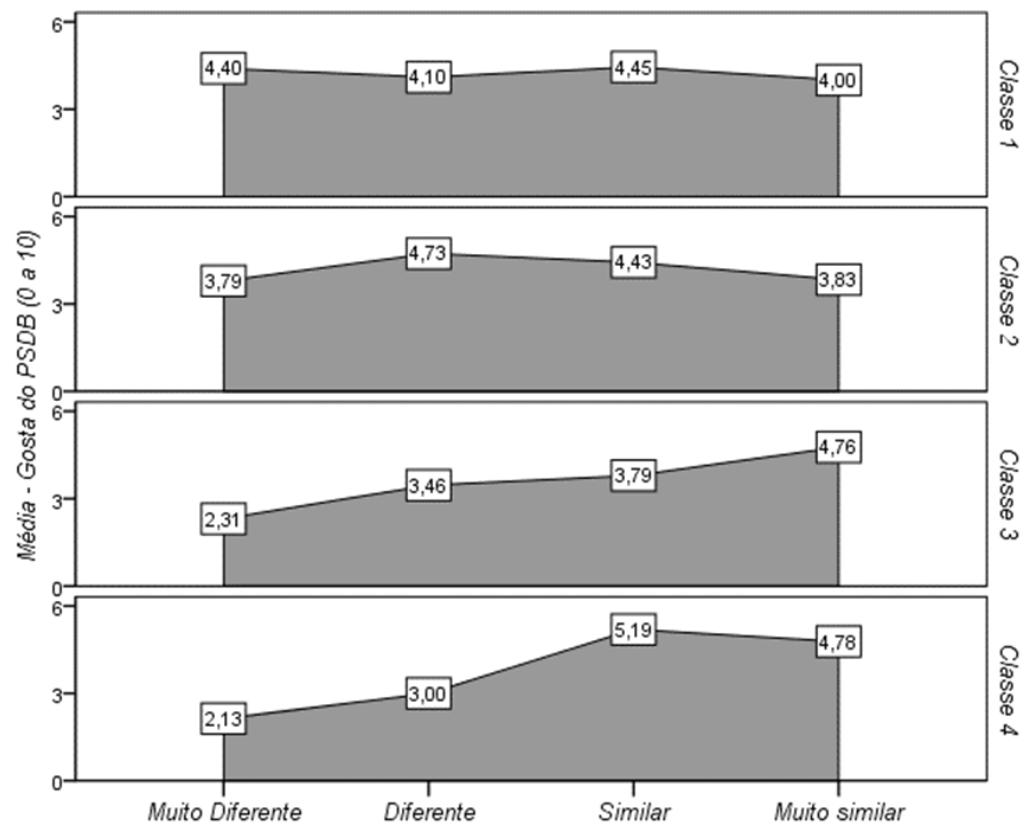

Fonte: APPC, elaboração própria.

Variáveis: Comparando com outras pessoas do bairro, você diria que a sua opinião política é: (1) = Muito Diferente; (2) = Diferente; (3) = Similar; (4) = Muito Similar, Classes de renda: $(1)=71$ a $80 \%<=2 \mathrm{SM}[\mathrm{N}=145],(2)=61$ a $70 \%<=2 \mathrm{SM}[\mathrm{N}=139],(3)=31$ a $60 \%<=2 \mathrm{SM}$ $[\mathrm{N}=145],(4)=0$ a $30 \%<=2 \mathrm{SM}[\mathrm{N}=124]$. 
Gráfico 4 - Média da opinião das pessoas sobre se gostam do PT (0 a 10), nos distritos agrupados por classe de renda, de acordo com a percepção do eleitor sobre se a sua opinião é similar ou diferente com relação à maioria.

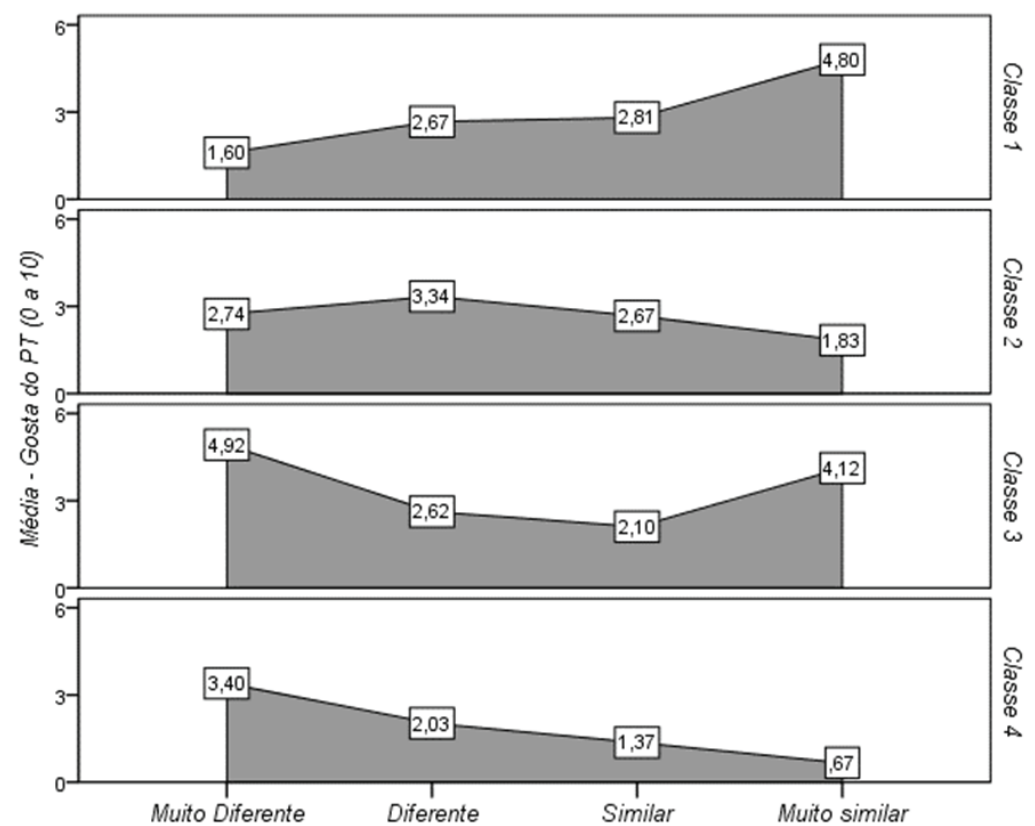

Fonte: APPC, elaboração própria.

Variáveis: Comparando com outras pessoas do bairro, você diria que a sua opinião política é: (1)

= Muito Diferente; $(2)=$ Diferente; $(3)=$ Similar; $(4)=$ Muito Similar; Classes de renda: $(1)=71$ a $80 \%<=2 \mathrm{SM}[\mathrm{N}=151],(2)=61$ a $70 \%<=2 \mathrm{SM}[\mathrm{N}=141],(3)=31$ a $60 \%<=2 \mathrm{SM}[\mathrm{N}=146]$, (4) $=0$ a $30 \%<=2 \mathrm{SM}[\mathrm{N}=123]$.

\section{Conclusão}

O contexto social e as interações interpessoais podem trazer informações que reforçam ou contradizem as opiniões políticas das pessoas. $\mathrm{O}$ que a nossa pesquisa mostrou é que as pessoas aparentemente conseguem ao mesmo tempo identificar a opinião majoritária do seu contexto de vizinhança e se sua opinião política é parecida ou diferente. Mais ainda, as pessoas que consideram sua opinião similar costumam conversar mais sobre política com os vizinhos do que aquelas que consideram ter uma opinião diferente.

Por não se tratar de uma pesquisa de "survey painel", a pesquisa não permite afirmar se em contextos de vizinhança mais homogêneos as 
opiniões são mais estáveis ao longo do tempo (Baker, Ames e Rennó, 2006). No entanto, encontramos evidências de que nesses contextos sociais homogêneos, as pessoas tendem a ter opiniões políticas mais polarizadas ao mesmo tempo que têm uma maior clareza quanto à sua opinião ser similar ou diferente dos seus vizinhos. Pelos dados da pesquisa, também não podemos afirmar categoricamente que as pessoas são influenciadas nas suas opiniões políticas pelo seu contexto social de vizinhança e pelas informações que ali circulam. Porém, podemos dizer que os eleitores têm consciência da opinião política historicamente majoritária do lugar onde moram, principalmente em contextos socialmente homogêneos, e que alteram seus padrões de interação social de acordo a similaridade ou diferença da sua própria opinião em relação à dos seus vizinhos.

$\mathrm{O}$ que os nossos resultados indicam é que as pessoas percebem se a sua opinião é condizente ou não com a majoritária do seu contexto social de vizinhança, ou seja, elas têm consciência da opinião majoritária dos residentes que compartilham da mesma localidade geográfica e se sua própria opinião é parecida. A questão a ser pesquisada em estudos futuros é se essa percepção altera a forma como o eleitor decide o seu voto, em outras palavras, se o contexto social onde ele vive influencia no seu comportamento eleitoral. $\mathrm{O}$ que $\mathrm{H} 2$ mostra é que o entrevistado modula o seu padrão de contato e comunicação política de acordo com essa percepção, indicando um caminho para pesquisas futuras de que talvez o eleitor paulista age de forma reativa em relação ao contato com os seus vizinhos (Miller 1977 apud Macallister et al. 2001), ou seja, a interação social no contexto de vizinhança apenas reforça sua opinião, a favor ou contra a maioria, ao invés de trazer informações que possam mudar sua posição política.

\section{Referências}

AGNEW, John (1987). Place and Politics: The Geographical Mediation of State and Society. Boston: Allen and Unwin.

AGNEW, John (1996). "Mapping Politics: How Context Counts in Electoral Geography”. Political Geography, v.15, n.2, p. 129-46. 
AGNEW, John (2002). Place and Politics in Modern Italy. Chicago: University of Chicago Press.

ARCHER, J. Clark.; TAYLOR, Peter J. (1981). Section and Party: A Political Geography of American Presidential Elections, from Andrew Jackson to Ronald Reagan. Chischester: Wiley.

ARCHER, J. Clark.; SHELLEY, Fred (1986). American electoral mosaics Resource publications in geography. Washington D. C: Association of American Geographers.

BAIL, Christopher A. (2018). "Exposure to opposing views on social media can increase political polarization". Proceedings of the National Academy of Sciences, v. 115 n. 37, p. 9216-9221.

BAKER, Andy; AMES, Barry; RENNÓ, Lucio R. (2006). "Social context and campaign volatility in new democracies: networks and neighborhoods in Brazil's 2002 elections". American Journal of Political Science, v. 50, n, 2, p. 382-399.

BAKSHY, Eytan; MESSING, Solomon; ADAMIC, Lada, (2015). "Exposure to ideologically diverse news and opinion on Facebook". Political Science, v. 348, n.6239, p. 1130-1132.

BAYBECK, Brady; HUCKFELDT, Robert (2002). "Urban contexts, spatially dispersed networks, and the diffusion of political information". Political Geography, v.21, n.2, p.195-220.

BERELSON, Bernard et al. (1954). Voting: A Study of Opinion Formation in a Presidential Election. Chicago: Univ. of Chicago Press.

BRAGA, Maria do Socorro S.; PIMENTEL Jr., Jairo (2011) “Os partidos políticos brasileiros realmente não importam?” Opinião Pública, Campinas, v.17, n.2, p. 271-303.

COX, Kevin (1969). "The voting decision in a spatial context". In: BOARD, R. J. et al. (ed.) Progress in Geography. London: Edward Arnold.

COUTO, Claudio G (2014). "Novas eleições críticas?” Em Debate, vol. 6, p. 17-24.

DOWNS, Anthony (1999). Uma teoria econômica da democracia. São Paulo: Edusp. 
FIGUEIREDO, Argelina C. et al (2002). "Partidos e distribuição espacial dos votos na cidade de São Paulo (1994-2000)". Novos Estudos, São Paulo: Cebrap, n.64, p. 153-176.

FIORINA, Morris P.; ABRAMS, Samuel J. (2008). "Political polarization in the American public". Annual Review of Political Science, v. 11, p. 563-588.

FRIZZO, Diogo (2013) Da Classe média à periferia? O PT nas eleições municipais paulistanas (1996-2012). Dissertação em Ciência Política. Universidade de São Paulo.

GRANOVETTER, Mark (1973). “The Strength of Weak Ties”. American Journal of Sociology, v.78, p.1360-80.

HOLZHACKER Denilde O; BALBACHEVSKY, Elizabeth (2007). "Classe, ideologia e política: uma interpretação dos resultados das eleições de 2002 e 2006”. Opinião Pública, v.13, n.2, p.283-306. HUCKFELDT, Robert (1979). "Political Participation and the Neighborhood Social Context". American Journal of Political Science, v. 23, n. 3, p.579-592.

HUCKFELDT, Robert (1986). Politics in Context: Assimilation and

Conflict in Urban Neighborhoods. New York: Agathon Press.

HUCKFELDT, Robert; JOHNSON, Paul E.; SPRAGUE, John (2004). The survival of diverse opinions within communication networks. New York: Cambridge University Press.

HUCKFELDT, Robert; PLUTZER, Eric; SPRAGUE, John (1993). "Alternative Contexts of Political Behavior: Churches, Neighborhoods, and Individuals". The Journal of Politics, v. 55, n. 2, p. 365-381.

HUCKFELDT, Robert; SPRAGUE, John (1987). "Networks in context: the social flow of political information". The American Political Science Review, v. 81, n.4, p.1197-1216.

JACOB, Cesar Romero et.al. (2010). A geografia do voto nas eleições presidenciais do Brasil: 1989-2006. Rio de Janeiro: Editora Vozes Ltda.

JOHNSTON, Ron (2019). "Political geographers and geographical political scientists - Crisis, what crisis?” Political Geography, v. 70 , p. 148-151. 
JOHNSTON, Ron; PATTIE, Charles (2006). Putting Voters in Their Place: Geography and Elections in Great Britain. New York: Oxford University Press.

JOHNSTON, Ron; PATTIE, Charles (2016). "Kevin Cox and Electoral Geography”. In: JONAS, Andrew E. G; WOOD, Andrew. (ed.) In Territory, the State and Urban Politics. New York: Routledge.

KELLERMAN, Aharon (2016). Geographic Interpretations of the internet. Haifa: Springer.

LAZARSFELD, Paul, F.; BERELSON, Bernard; GAUDET, Hazel (1948). The People's Choice: How the Voter Makes Up His Mind in a Presidential Campaign. New York: Columbia University Press.

LIMONGI, Fernando; MESQUITA, Lara (2008). "Estratégia partidária e preferência dos eleitores. As eleições municipais em São Paulo entre 1985 e 2004". Novos Estudos, Cebrap, n.81.

LINKE, Andrew. M.; O'LOUGHLIN, John (2015). "Spatial Analysis". In: AGNEW, J. et. al. The Wiley Blackwell Companion to Political Geography. Chischester, UK: John Wiley \& Sons, Ltd. MACALLISTER, Ian et al (2001). "Class Dealignment and the Neighbourhood Effect: Miller Revisited". British Journal of Political Science, v.31, p. 41-59.

MOK, Diana; WELLMAN, Barry; CARRASCO, Juan (2010). "Does Distance Matter in the Age of the Internet?" Urban Studies, v.47, n.13, p.2747-2783.

MUTZ, Diana, C.; MONDAK, Jefferey, J. (2006). “The Workplace as a Context for Cross-Cutting Political Discourse". The Journal of Politics, v. 68, n. 1, p. 140-155.

NOVAES, Carlos A. M. (1996). "O primeiro turno da eleição para prefeito em São Paulo". Novos Estudos, Cebrap. São Paulo, n. 46. O'LOUGHLIN, John (2018). "Thirty-five years of political geography and Political Geography: The good, the bad and the ugly". Political Geography, v. 65, p. 143-151

OPENSHAW, Stan (1983). The Modifiable Areal Unit Problem. Norwich: Geo Books. 
PIERUCCI, Antônio F. (1987) "As bases da nova direita". Novos Estudos, Cebrap. São Paulo, n.19.

PIERUCCI, Antônio F. (1989) "A direita mora do outro lado da cidade". Revista Brasileira de Ciências Sociais. Associação Nacional de Pós-Graduação e Pesquisa em Ciências Sociais (Anpocs), v.4, n.10.

REIS, Fábio Wanderley (2014). “Eleição de 2014: 'país dividido' e questão social”. Em Debate, vol. 6, p. 8-1.

SAMUELS, David J.; ZUCCO, Cesar (2014). “The Power of

Partisanship in Brazil: Evidence from Survey Experiments". American Journal of Political Science, v. 58, n. 1, p. 212-225.

SAMUELS, David J.; ZUCCO, Cesar (2018). Partisans, Antipartisans, and Nonpartisans: Voting Behavior in Brazil. Cambridge University Press.

SOUKUP, Charles (2006). "Computer-mediated communication as a virtual third place: building Oldenburg's great good places on the world wide web”. New Media \& Society, v. 8, n. 3, p. 421-440. TOBLER, Waldo. R. (1989). "Frame Independent Spatial Analysis". In: GOODCHILD, M. F; GOPAL, S. (ed.) The Accuracy of Spatial Databases. London: Taylor and Francis, p.115-22.

\section{Anexo 1}

Variância acumulada da análise fatorial do modelo "S" aplicada para os resultados em porcentagem de PT e PSDB no primeiro turno das eleições presidenciais de 2006 a 2014 na escala dos distritos administrativos da cidade de São Paulo.

\begin{tabular}{ccccccc}
\hline & \multicolumn{3}{c}{ Valores próprios iniciais } & \multicolumn{3}{c}{ Somas de extração de carregamentos ao quadrado } \\
\hline Componente & Total & \% de var. & \% cum. & Total & \% de var. & $\%$ cum. \\
\hline 1 & 68,943 & 71,816 & 71,816 & 68,943 & 71,816 & 71,816 \\
\hline 2 & 25,834 & 26,91 & 98,726 & 25,834 & 26,91 & 98,726 \\
\hline 3 & 0,718 & 0,747 & 99,474 & & & \\
\hline 4 & 0,471 & 0,49 & 99,964 & & & \\
\hline 5 & 0,034 & 0,036 & 100 & & & \\
\hline
\end{tabular}

Fonte: Elaboração própria. 


\section{Anexo 2}

Número e proporção de entrevistas por distrito administrativo da cidade de São Paulo

\begin{tabular}{|c|c|c|c|}
\hline Número & Distritos & Frequência & Porcentual \\
\hline 1 & ÁGUA RASA & 12 & 1,2 \\
\hline 2 & ALTO DE PINHEIROS & 12 & 1,2 \\
\hline 3 & ARICANDUVA & 12 & 1,2 \\
\hline 4 & ARTUR ALVIM & 25 & 2,5 \\
\hline 5 & BELA VISTA & 11 & 1,1 \\
\hline 6 & BELÉM & 12 & 1,2 \\
\hline 7 & BUTANTÃ & 12 & 1,2 \\
\hline 8 & CACHOEIRINHA & 25 & 2,5 \\
\hline 9 & CAMBUCI & 12 & 1,2 \\
\hline 10 & CAMPO BELO & 12 & 1,2 \\
\hline 11 & CAMPO GRANDE & 12 & 1,2 \\
\hline 12 & CANGAIBA & 22 & 2,2 \\
\hline 13 & CARRÃO & 12 & 1,2 \\
\hline 14 & CASAVERDE & 14 & 1,4 \\
\hline 15 & CONSOLAÇÃOO & 12 & 1,2 \\
\hline 16 & CURSINO & 23 & 2,3 \\
\hline 17 & FREGUESIA DO Ó & 25 & 2,5 \\
\hline 18 & IPIRANGA & 12 & 1,2 \\
\hline 19 & ITAIM BIBI & 12 & 1,2 \\
\hline 20 & JABAQUARA & 49 & 4,9 \\
\hline 21 & JAÇANÁ & 12 & 1,2 \\
\hline 22 & JAGUARÉ & 12 & 1,2 \\
\hline 23 & JARDIM PAULISTA & 12 & 1,2 \\
\hline 24 & LAPA & 13 & 1,3 \\
\hline 25 & LIBERDADE & 12 & 1,2 \\
\hline 26 & LIMÃO & 11 & 1,1 \\
\hline 27 & MANDAQUI & 24 & 2,4 \\
\hline 28 & MOEMA & 12 & 1,2 \\
\hline 29 & MOOCA & 12 & 1,2 \\
\hline 30 & PENHA & 23 & 2,3 \\
\hline
\end{tabular}




\begin{tabular}{|c|c|c|c|}
\hline 31 & PERDIZES & 24 & 2,4 \\
\hline 32 & PINHEIROS & 12 & 1,2 \\
\hline 33 & PIRITUBA & 24 & 2,4 \\
\hline 34 & PONTE RASA & 12 & 1,2 \\
\hline 35 & REPÚBLICA & 12 & 1,2 \\
\hline 36 & RIO PEQUENO & 24 & 2,4 \\
\hline 37 & SACOMÃ & 46 & 4,6 \\
\hline 38 & SANTA CECÍLIA & 11 & 1,1 \\
\hline 39 & SANTANA & 24 & 2,4 \\
\hline 40 & SANTO AMARO & 13 & 1,3 \\
\hline 41 & SÃODOMINGOS & 12 & 1,2 \\
\hline 42 & SÃOLUCAS & 25 & 2,5 \\
\hline 43 & SAÚDE & 24 & 2,4 \\
\hline 44 & SOCORRO & 13 & 1,3 \\
\hline 45 & TATUAPÉ & 12 & 1,2 \\
\hline 46 & TREMEMBÉ & 32 & 3,2 \\
\hline 47 & TUCURUVI & 12 & 1,2 \\
\hline 48 & VILA ANDRADE & 24 & 2,4 \\
\hline 49 & VILAFORMOSA & 12 & 1,2 \\
\hline 50 & VILA GUILHERME & 13 & 1,3 \\
\hline 51 & VILA LEOPOLDINA & 12 & 1,2 \\
\hline 52 & VILA MARIA & 24 & 2,4 \\
\hline 53 & VILA MARIANA & 26 & 2,6 \\
\hline 54 & VILA MATILDE & 24 & 2,4 \\
\hline 55 & VILA MEDEIROS & 24 & 2,4 \\
\hline 56 & VILA PRUDENTE & 25 & 2,5 \\
\hline \multirow[t]{2}{*}{57} & VILA SONIA & 11 & 1,1 \\
\hline & Total & 1008 & 100 \\
\hline
\end{tabular}




\section{Anexo 3}

Número e proporção de entrevistas por sexo, idade, escolaridade, PEA e renda.

\begin{tabular}{|c|c|c|}
\hline Variável & Frequência & Porcentual \\
\hline \multicolumn{3}{|l|}{ Idade } \\
\hline De 16a 24 anos & 138 & 13,7 \\
\hline De 25 a 44 anos & 424 & 42,1 \\
\hline De 45 a 59 anos & 253 & 25,1 \\
\hline Mais de 60 anos & 193 & 19,1 \\
\hline Total & 1008 & 100 \\
\hline \multicolumn{3}{|l|}{ Escolaridade } \\
\hline Fundamental & 196 & 19,4 \\
\hline Ensino Médio & 378 & 37,5 \\
\hline Ensino Superior & 434 & 43,1 \\
\hline Total & 1008 & 100 \\
\hline \multicolumn{3}{|l|}{ PEA } \\
\hline Sim & 665 & 66 \\
\hline Não & 342 & 33,9 \\
\hline NS/NR & 1 & 0,1 \\
\hline Total & 1008 & 100 \\
\hline \multicolumn{3}{|l|}{ Renda Familiar } \\
\hline Até2 Salários Mínimos & 324 & 32,1 \\
\hline Mais de 2 Salários Mínimos & 612 & 60,7 \\
\hline Não Sabe & 72 & 7,1 \\
\hline Total & 1008 & 100 \\
\hline
\end{tabular}

\section{Anexo 4}

Frequência e proporção das perguntas utilizadas na pesquisa e contidas no Survey.

\begin{tabular}{ccccc}
\hline Gosta do (0a 10) & \multicolumn{2}{c}{ PT } & \multicolumn{2}{c}{ PSDB } \\
\hline & Frequência & Porcentual & Frequência & Porcentual \\
\hline 0 & 460 & 45,6 & 234 & 23,2 \\
\hline 1 & 56 & 5,6 & 46 & 4,6 \\
\hline 2 & 44 & 4,4 & 65 & 6,4 \\
\hline
\end{tabular}




\begin{tabular}{ccccc}
\hline 3 & 46 & 4,6 & 66 & 6,5 \\
\hline 4 & 34 & 3,4 & 56 & 5,6 \\
\hline 5 & 113 & 11,2 & 194 & 19,2 \\
\hline 6 & 28 & 2,8 & 48 & 4,8 \\
\hline 7 & 30 & 3,0 & 46 & 4,6 \\
\hline 8 & 38 & 3,8 & 63 & 6,3 \\
\hline 9 & 15 & 1,5 & 24 & 2,4 \\
\hline 10 & 53 & 5,3 & 51 & 5,1 \\
\hline NS/NR & 91 & 9,0 & 115 & 11,4 \\
\hline Total & 1008 & 100 & 1008 & 100 \\
\hline
\end{tabular}

Você costuma conversar sobre política com os seus vizinhos? Sim ou não

\begin{tabular}{ccc} 
Sim & 347 & 34,4 \\
Não & 656 & 65,1 \\
\hline NS/NR & 5 & 0,5 \\
\hline Total & 1008 & 100,0
\end{tabular}

\begin{tabular}{ccc}
$\begin{array}{c}\text { Comparando com as outras pessoas do seu } \\
\text { bairro, você diria que a sua opinião política é: }\end{array}$ & Frequência & Porcentual \\
\hline Muito Diferente & 75 & 7,4 \\
\hline Diferente & 197 & 19,5 \\
\hline Similar & 302 & 30,0 \\
\hline Muito similar & 54 & 5,4 \\
\hline NS/NR & 380 & 37,7 \\
\hline Total & 1008 & 100,0 \\
\hline
\end{tabular}

\begin{tabular}{ccc}
\hline \multicolumn{4}{c}{ Pelo o que você sabe ou ouviu falar, qual o partido político mais forte no seu bairro? } \\
\hline Partidos & Frequência & Porcentual \\
\hline PT & 150 & 14,9 \\
\hline PSDB & 186 & 18,5 \\
\hline PMDB & 31 & 3,1 \\
\hline PV & 3 & 0,3 \\
\hline PDT & 3 & 0,3 \\
\hline PPS & 1 & 0,1 \\
\hline PSB & 1 & 0,1 \\
\hline
\end{tabular}




\begin{tabular}{ccc}
\hline PP & 1 & 0,1 \\
\hline PTB & 2 & 0,2 \\
\hline PC do B & 2 & 0,2 \\
\hline PSD & 2 & 0,2 \\
\hline PSOL & 3 & 0,3 \\
\hline PC do B & 1 & 0,1 \\
\hline Partido Novo & 1 & 0,1 \\
\hline Outros & 6 & 0,6 \\
\hline Nenhum & 92 & 9,1 \\
\hline Nãosabe/Não Respondeu & 523 & 51,9 \\
\hline Total & 1008 & 100 \\
\hline
\end{tabular}

\section{Anexo 5}

Distritos Divididos por classe de renda.

\begin{tabular}{|c|c|c|c|}
\hline \multicolumn{4}{|c|}{ Número de residentes que ganham menos de 2 salários mínimos (censo do IBGE 2010) } \\
\hline Distritos & Residentes com <2SM & Frequência & Porcentual \\
\hline Classe 1 & 71 a $80 \%$ & 295 & 29,3 \\
\hline Classe 2 & 61 a $70 \%$ & 231 & 22,9 \\
\hline Classe 3 & 31 a $60 \%$ & 275 & 27,3 \\
\hline Classe 4 & 0 a $30 \%$ & 207 & 20,5 \\
\hline \multicolumn{2}{|c|}{ Total } & 1008 & 100 \\
\hline
\end{tabular}

\section{Resumo}

O presente artigo busca apresentar evidências sobre a influência do contexto social e geográfico na percepção e comunicação política das pessoas por meio dos resultados de uma pesquisa de survey realizada na cidade de São Paulo no ano de 2016. Os dados dessa pesquisa mostram que nos distritos mais ricos e centrais da cidade de São Paulo, regiões que historicamente têm apoiado o PSDB em eleições locais e nacionais, o eleitor mediano parece ter consciência sobre qual é o partido mais forte no seu bairro ao mesmo tempo que consegue determinar se sua opinião política é parecida ou diferente da maioria, principalmente em bairros socialmente homogêneos. Mais ainda, aquele eleitor que considera sua opinião diferente tende a conversar menos sobre política com os seus 
vizinhos sugerindo que o eleitor modula o padrão de interação social no seu contexto de vizinhança para evitar o desacordo.

Palavras chaves: geografia eleitoral, comportamento eleitoral, efeitos contextuais, interação social.

\section{Abstract}

This article presents evidences about the influence of social and geographic context on people's political perception and communication analysing data of a survey research conducted in São Paulo in 2016. This research shows that in the richest districts of São Paulo, regions where PSDB has historical support in local and national elections, the average elector seems to know which party is the strongest in his neighbourhood. At the same time, this elector can determine whether his political opinion is similar or not in relation to the majority, mainly in social homogeneous neighbourhoods. Furthermore, if the elector assumes that his opinion is different, he talks less about politics with his neighbours, suggesting that he modulates social interaction patterns in his neighbourhood context to avoid disagreement.

Keywords: electoral geography, electoral behaviour, context effects, social interaction.

Recebido em 25 de maio de 2019

Aprovado em 01 de agosto de 2019 